\title{
Vitamin C supplementation in relation to inflammation in individuals with atrophic gastritis: a randomised controlled trial in Japan
}

\author{
Enbo $\mathrm{Ma}^{1}$, Shizuka Sasazuki ${ }^{2 *}$, Satoshi Sasaki ${ }^{3}$, Yoshitaka Tsubono ${ }^{2}$, Shunji Okubo ${ }^{4}$ and \\ Shoichiro Tsugane ${ }^{2}$ \\ ${ }^{1}$ Department of Epidemiology, Faculty of Medicine, University of Tsukuba, Ibaraki 305-8575, Japan \\ ${ }^{2}$ Epidemiology and Prevention Division, Research Center for Cancer Prevention and Screening, National Cancer Research \\ Center, 5-1-1 Tsukiji, Chuo-ku, Tokyo 104-0045, Japan \\ ${ }^{3}$ Department of Social and Preventive Epidemiology, Graduate School of Medicine, University of Tokyo, Tokyo 113-0033, \\ Japan \\ ${ }^{4}$ Hiraka General Hospital, Akita 013-8610, Japan \\ (Submitted 7 March 2012 - Final revision received 17 May 2012 - Accepted 17 May 2012 - First published online 24 July 2012)
}

\section{Abstract}

Evidence has shown that both C-reactive protein (CRP) and serum amyloid component A (SAA) are increased in individuals with gastritis and stomach cancer. Controlling the level of these biomarkers by inhibiting the gastric infection with high doses of ascorbic acid may reduce the risk of carcinogenesis. A population-based double-blind randomised controlled trial in a Japanese population with atrophic gastritis in an area of high stomach cancer incidence was conducted between 1995 and 2000. Daily doses of 50 or $500 \mathrm{mg}$ vitamin C were given, and 120 and 124 participants completed the 5-year study, respectively. Although serum ascorbic acid was higher in the high-dosage group $(1.73(\mathrm{sD} 0.46) \mu \mathrm{g} / \mathrm{l})$ than in the low-dosage group (1.49 (SD 0.29) $\mu \mathrm{g} / 1, P<0.001$ ), at the end of the study, no significant difference was observed for CRP between the low- and high-dosage groups (0.39 (95\% CI 0.04, 4.19) mg/l and 0.38 (95\% CI 0.03, $4.31) \mathrm{mg} / \mathrm{l}$, respectively; $P=0.63$ ) or for SAA between the low- and high-dosage groups (3.94 (95\% CI $1.04,14.84) \mu \mathrm{g} / \mathrm{ml}$ and 3.85 (95\% CI $0.99,14.92) \mu \mathrm{g} / \mathrm{ml}$, respectively; $P=0.61)$. Vitamin $\mathrm{C}$ supplementation may not have a strong effect on reducing infections in individuals with atrophic gastritis.

\section{Key words: Ascorbic acid: C-reactive protein: Serum amyloid component A: Atrophic gastritis}

Chronic gastritis, caused by Helicobacter pylori infection, is an early-stage precursor for gastric adenocarcinoma ${ }^{(1,2)}$. However, gastric carcinogenesis may result from a combination of factors, particularly in individuals who react strongly to inflammation or demonstrate a strong immune response ${ }^{(3)}$. C-reactive protein (CRP) and serum amyloid component A (SAA) are acute-phase inflammatory reactants in the human body that increase in parallel ${ }^{(3,4)}$. Evidence has shown that both CRP and SAA are increased in individuals with gastritis and stomach cancer ${ }^{(3,5,6)}$. Vitamin $\mathrm{C}$ has been suggested to have roles in inhibiting the growth of $H$. pylori, inhibiting intragastric formation of nitrosamines and regulating the immune response $\mathrm{e}^{(7-9)}$. Controlling the level of these biomarkers may reduce the risk of carcinogenesis in the stomach. Therefore, we hypothesise that a high serum level of ascorbic acid may reduce stomach cancer risk via control of the inflammatory markers CRP and SAA.
A population-based double-blind randomised controlled trial in a Japanese population with gastritis in an area of high stomach cancer incidence was conducted between 1995 and 2000, with the aim of examining the effect of vitamin $\mathrm{C}$ supplementation on the primary prevention of gastric cancer $^{(10,11)}$. We report the impact of vitamin $C$ supplementation on CRP and SAA status in trial subjects at the end of the 5-year period.

\section{Materials and methods}

\section{Study participants}

The trial was initially intended to examine the effects of supplementation with $\beta$-carotene (0 or $15 \mathrm{mg} / \mathrm{d}$ ) and vitamin $\mathrm{C}$ ( 50 or $500 \mathrm{mg} / \mathrm{d}$ ) on the incidence of gastric cancer, whereby participants were randomised in a double-blind manner to one of four groups by using a $2 \times 2$ factorial design. A total

Abbreviations: CRP, C-reactive protein; PG, pepsinogen; SAA, serum amyloid component A

*Corresponding author: S. Sasazuki, fax +8133547 8578, email ssasazuk@ncc.go.jp 
of 1231 subjects who were aged 40-69 years and living in four municipalities of the Yokote Public Health Center District of Akita Prefecture were selected to participate in the randomised clinical trial. After the first year of participants' recruitment in $1995, \beta$-carotene supplementation was reported to have potential harmful effects for individuals at high risk for lung cancer ${ }^{(12,13)}$, and the study protocol was modified by removing subjects who were using $\beta$-carotene and stopping recruitment of new subjects in three municipalities ${ }^{(10)}$. The primary endpoint of the trial was changed from a 10-year accumulated incidence of gastric cancer to 5-year changes of the serum levels of pepsinogen (PG) and other biomarkers ${ }^{(10)}$. The present study was conducted according to the guidelines laid down in the Declaration of Helsinki and all procedures involving patients were approved by the ethics committee of the National Cancer Center and the Hiraka General Hospital. Written informed consents were obtained from all individuals willing to participant and those remaining in the study. Finally, 120 and 124 subjects in the low-dosage and high-dosage groups of vitamin $\mathrm{C}$ supplementation, respectively, completed the 5-year study (Fig. 1). The details of the study rationale, design, methodology and protocol amendment have been described previously ${ }^{(10,11)}$.
Eligible subjects were diagnosed with chronic atrophic gastritis by the cut-off value of PGI $<70 \mathrm{ng} / \mathrm{ml}$ and a ratio of PGI:II of $<3.0$, of which the sensitivity was $80 \%$ and specificity was $70 \%$ as reported ${ }^{(14)}$. Miki $^{(15)}$ reported that the values measured by the same kit showed a good correlation (correlation coefficient 0.983 for PGI, 0.991 for PGII and 0.935 for PGI:II) with those measured by RIA (PGI/PGII RIA-BEAD; Dinabot Company Limited), in which a sensitivity of $70.5 \%$ and a specificity of $97.0 \%$ for atrophic gastritis, compared with histology, have been reported ${ }^{(16)}$. Selection criteria were no history of gastric cancer or related surgery; no history of cirrhosis, liver cancer or other cancer within the last 5 years; no abnormal liver function; no use of diet supplements containing $\beta$-carotene or vitamin $C$; and no expectation of moving outside the study area within 1 year.

\section{Participant follow-up and dietary intake assessment}

Participants were asked to visit the community centres every 3 months where their clinical symptoms and side effects from vitamin $\mathrm{C}$ supplementation were assessed, compliance was checked based on the number of unconsumed capsules, and capsules for further use were dispensed ${ }^{(10,11)}$. Compliance averaged 92.6 and $92.2 \%$ in the low- and high-dosage groups,

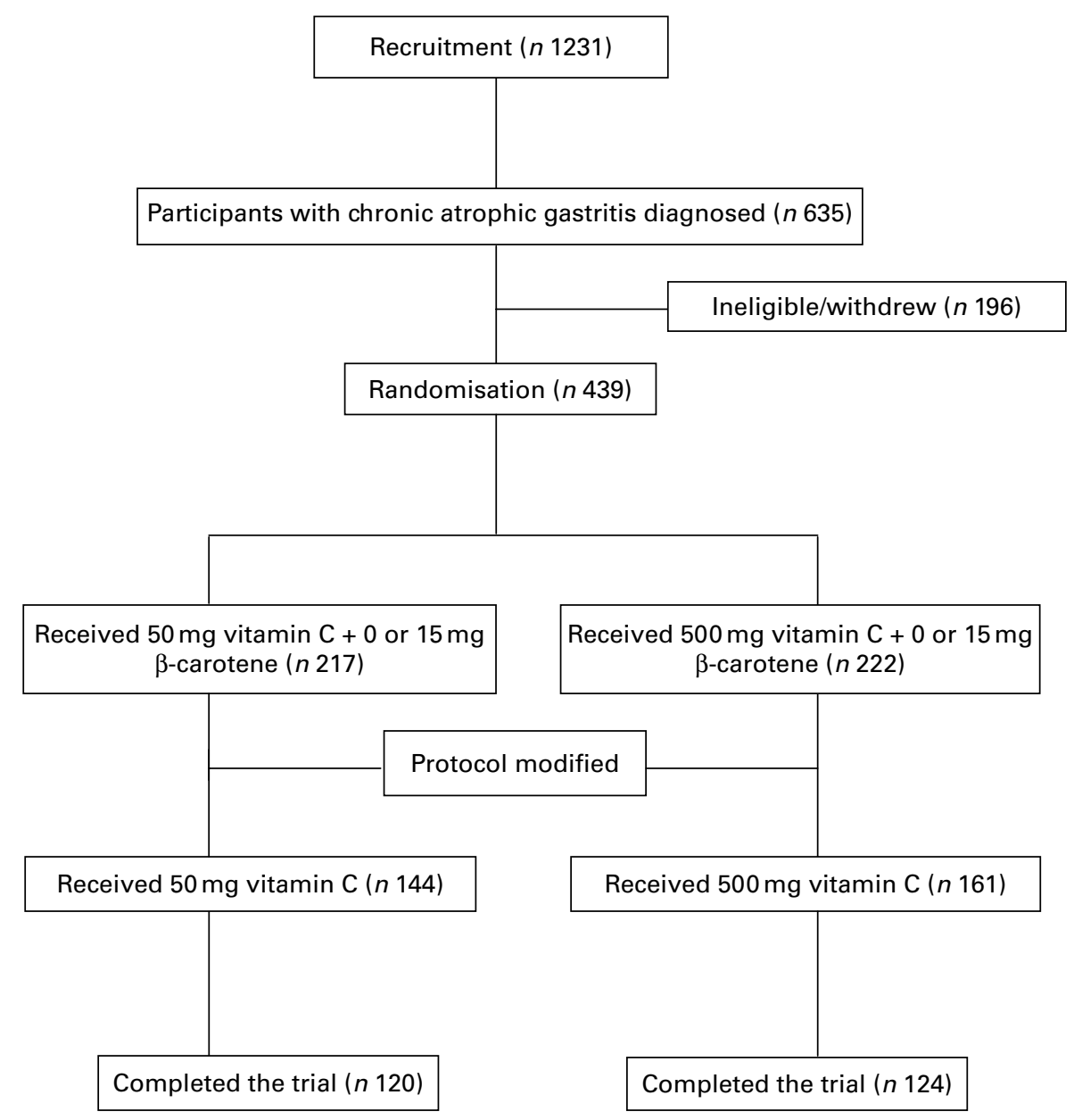

Fig. 1. Flow chart of participant recruitment before and after the protocol amendment and of participants at the 5-year follow-up. 
respectively $^{(17)}$. A validated 138-item FFQ was used to assess dietary intake, for which participants were asked how often they consumed individual food items and to estimate the representative size of their portions relative to the size of a standard portion. Daily intake of vitamin C and other nutrients were calculated by using the fifth revised and enlarged edition of the Standard Tables of Food Composition in Japan $^{(18)}$. The details of the FFQ have been described in a previous report ${ }^{(11,17)}$.

\section{Biochemical analysis}

Fasting blood samples were collected at baseline and after 5 years and analysed for serum ascorbic acid levels, CRP and SAA. The subjects were asked not to eat or drink anything except water after 21.00 hours on the day before blood sampling. The serum was sampled between 07.00 and 10.00 hours. All samples were stored at -70 to $-85^{\circ} \mathrm{C}$ and were analysed simultaneously after completion of the 5-year follow-up. All assays were conducted by persons who were blinded as to the intervention assignment and the questionnaire data.

Serum for ascorbic acid measurement was stabilised by the addition of metaphosphoric acid, and serum ascorbic acid concentration was measured fluorimetrically (iodine oxidation and condensation with 1,2-phenylenediamine). CRP and SAA concentrations were determined by the latex agglutination nephelometric immunoassay test (LZ test 'Eiken' CRP-HG and LZ test 'Eiken' SAA, respectively; Eiken Kagaku Company Limited). IgG antibodies to $H$. pylori were measured with a direct ELISA kit (E Plate 'Eiken' H. pylori antibody; Eiken Kagaku Company Limited). Levels of IgG were categorised as seropositive and seronegative for H. pylori according to the selected cut-off value $(492 \mathrm{~nm})^{(19)}$.

\section{Statistical analysis}

We followed the intent-to-treat analysis, which included all subjects remaining in the study after the protocol was modified. The per-protocol analysis included subjects who completed the study to the 5-year follow-up. Baseline comparisons between the low- and high-dosage groups and the dropout group as the control were examined by one-way ANOVA for continuous variables and by the $\chi^{2}$ test for categorical variables. Differences of values within the lowand high-dosage groups were tested by the paired $t$ test for continuous variables and by the one-sample $z$ test for proportions.

CRP was categorised into positive and negative groups by using a cut-off point of $1.8 \mathrm{mg} / 1$, while SAA was grouped as positive or negative based on a cut-off point of $8.0 \mu \mathrm{g} / \mathrm{ml}^{(3)}$. Subjects' status on combined biomarkers of CRP and SAA was determined by the defined positive and negative statuses of CRP and SAA. Log transformation was done for dietary intake of vitamin $\mathrm{C}$, serum CRP and SAA, and H. pylori titre when conducting the comparisons between the two dosage groups; and data are presented as geometric means with their standard errors. The difference between the two dosage groups for changes in CRP and SAA at the end of the 5-year follow-up compared with baseline was calculated by using the geometric means, respectively.

Adjusted analysis of the means of serum CRP and SAA for covariates was performed by one-way ANOVA. Results were adjusted for age (continuous), sex, dietary intake of vitamin $\mathrm{C}$ (quartile), alcohol consumption (never or occasional, regular), smoking status (never, ever), BMI $\left(<25, \geq 25 \mathrm{~kg} / \mathrm{m}^{2}\right)$, H. pylori status (no, yes) and menopausal status (no, yes, for women). Stratified analysis was performed for age groups, alcohol consumption, smoking status, BMI and menopausal status. $P$ values less than 0.05 in two-tailed tests were considered as significant, and all statistical analyses were performed using SAS version 9.1 (SAS Institute).

\section{Results}

The baseline characteristics of the trial participants are shown in Table 1. Subjects in the low-dosage group were older than those in the high-dosage group. There were more CRP-positive subjects in the high-dosage group than in the low-dosage group both in the intent-to-treat and per-protocol analyses (borderline significance). H. pylori titres were higher in the high-dosage group than in the low-dosage group, with a significant difference in the per-protocol analysis.

At the 5-year follow-up, serum ascorbic acid was higher in the high-dosage group (increased $0.37 \mu \mathrm{g} / \mathrm{l}$ ) compared with the low-dosage group (increased $0 \cdot 10 \mu \mathrm{g} / \mathrm{l}$ from baseline, $P<0 \cdot 001$ ) (Table 2). Correlation of the log-transformed CRP and SAA in all participants at the 5-year follow-up was 0.541 $(P<0.001)$. A slight increase in the low-dose group and a decrease in the high-dose group both in CRP and SAA levels were observed at the 5-year follow-up; thus the absolute $0.07 \mathrm{mg} / \mathrm{l}$ reductions in CRP and the $0.31 \mu \mathrm{g} / \mathrm{ml}$ reduction in SAA were in the high-dose group compared with those in the low-dose group, if taking consideration of the baseline values. However, there were no significant differences for CRP between the low- and high-dosage groups (0.39 (95\% CI $0 \cdot 04,4 \cdot 19) \mathrm{mg} / 1$ and $0.38(95 \%$ CI $0 \cdot 03,4 \cdot 31) \mathrm{mg} / \mathrm{l}$, respectively; $P=0.63)$ or for SAA between the low- and high-dosage groups $(3.94(95 \%$ CI $1.04,14.84) \mu \mathrm{g} / \mathrm{ml}$ and 3.85 (95\% CI 0.99, 14.92$) \mu \mathrm{g} / \mathrm{ml}$, respectively; $P=0.61$ ) (Table 2). CRP status changed from positive to negative for $60 \%$ (six out of ten) of the low-dosage group and $68.4 \%$ (thirteen out of nineteen) of the high-dosage group between baseline and the 5-year follow-up $(P=0.33)$, while SAA status for $57.1 \%$ (eight out of fourteen) in the low-dosage group and $70 \cdot 0 \%$ (seven out of ten) in the high-dosage group of SAA-positive participants changed from positive to negative $(P=0 \cdot 27)$. The combined positive and negative statuses for CRP and SAA were also not significantly different between the two groups at the 5 -year follow-up ( $47 \cdot 4 \%$ (nine out of nineteen) $v .59 \cdot 1 \%$ (thirteen out of twenty-two); $P=0 \cdot 23$ ). When we deleted two outliers that were both CRP- and SAA-positive at baseline, similar null results for CRP and SAA were observed, respectively, between the two dosage groups at the 5-year follow-up. 
Table 1. Baseline characteristics of the participants in the trial

(Mean values and standard deviations or standard errors; number of participants and percentages)

\begin{tabular}{|c|c|c|c|c|c|c|c|c|c|c|}
\hline & \multicolumn{5}{|c|}{ Intent-to-treat } & \multicolumn{5}{|c|}{ Per-protocol } \\
\hline & \multicolumn{2}{|c|}{$\begin{array}{c}\text { Low-dosage } \\
\text { vitamin C, } \\
50 \mathrm{mg}(n 144)\end{array}$} & \multicolumn{2}{|c|}{$\begin{array}{c}\text { High-dosage } \\
\text { vitamin C, } \\
500 \mathrm{mg}(n 161)\end{array}$} & \multirow[b]{2}{*}{$P^{*}$} & \multicolumn{2}{|c|}{$\begin{array}{c}\text { Low-dosage } \\
\text { vitamin C, } \\
50 \mathrm{mg}(n 120)\end{array}$} & \multicolumn{2}{|c|}{$\begin{array}{c}\text { High-dosage } \\
\text { vitamin C, } \\
500 \mathrm{mg}(n 124)\end{array}$} & \multirow[b]{2}{*}{$P^{*}$} \\
\hline & $n$ & $\%$ & $n$ & $\%$ & & $n$ & $\%$ & $n$ & $\%$ & \\
\hline Age (years) & \multirow{2}{*}{\multicolumn{2}{|c|}{58.56}} & & & 0.01 & & & & & 0.02 \\
\hline Mean & & & \multicolumn{2}{|c|}{$56 \cdot 55$} & & \multicolumn{2}{|c|}{$58 \cdot 67$} & \multicolumn{2}{|c|}{$56 \cdot 29$} & \\
\hline SD & \multicolumn{2}{|c|}{6.64} & \multicolumn{2}{|c|}{$8 \cdot 74$} & & \multirow{2}{*}{\multicolumn{2}{|c|}{6.53}} & \multicolumn{2}{|c|}{8.66} & \\
\hline BMI $\left(\mathrm{kg} / \mathrm{m}^{2}\right)$ & & & & & 0.66 & & & & & 0.52 \\
\hline Mean & \multicolumn{2}{|c|}{23.38} & \multicolumn{2}{|c|}{$23 \cdot 18$} & & \multicolumn{2}{|c|}{23.42} & \multicolumn{2}{|c|}{$23 \cdot 23$} & \\
\hline SD & \multicolumn{2}{|c|}{2.92} & \multicolumn{2}{|c|}{2.69} & & \multicolumn{2}{|c|}{2.86} & \multicolumn{2}{|c|}{2.65} & \\
\hline Men & 54 & 37.5 & 58 & $36 \cdot 0$ & 0.79 & 41 & $34 \cdot 2$ & 45 & $36 \cdot 3$ & 0.73 \\
\hline Current smoking & 18 & 12.5 & 26 & $16 \cdot 2$ & 0.65 & 12 & $10 \cdot 0$ & 19 & $15 \cdot 3$ & 0.38 \\
\hline Alcohol consumption & 62 & $43 \cdot 1$ & 69 & $42 \cdot 9$ & 0.99 & 53 & $42 \cdot 2$ & 57 & $46 \cdot 0$ & 0.69 \\
\hline Serum ascorbic acid $(\mu \mathrm{g} / \mathrm{l})$ & 1.37 & 0.35 & 1.35 & 0.37 & 0.96 & 1.38 & 0.32 & 1.35 & 0.37 & 0.51 \\
\hline Dietary vitamin $C(\mu \mathrm{g} / \mathrm{l})$ & & & & & 0.65 & & & & & 0.41 \\
\hline Mean & \multicolumn{2}{|c|}{121.03} & & & & & & & & \\
\hline SE & & & & & & & & & & \\
\hline CRP $(\mathrm{mg} / \mathrm{l}) \dagger$ & & & & & 0.16 & & & & & 0.77 \\
\hline Mean & & & & & & & & & & \\
\hline SE & & & & & & & & & & \\
\hline CRP positive $\dagger$ & 11 & $7 \cdot 6$ & 24 & 14.9 & 0.05 & 10 & $8 \cdot 3$ & 19 & $15 \cdot 3$ & 0.07 \\
\hline $\mathrm{SAA}(\mu \mathrm{g} / \mathrm{ml}) \dagger$ & & & & & 0.26 & & & & & 0.29 \\
\hline Mean & & & & & & & & & & \\
\hline SE & & & & & & & & & & \\
\hline SAA positive† & 16 & $11 \cdot 1$ & 16 & 9.9 & 0.74 & 14 & $11 \cdot 7$ & 10 & $8 \cdot 1$ & 0.35 \\
\hline Helicobacter pylori titre (RU/ml) & & & & & 0.15 & & & & & 0.01 \\
\hline Mean & & & & & & & & & & \\
\hline SE & & & & & & & & & & \\
\hline H. pylori positive & 140 & $97 \cdot 2$ & 157 & 97.5 & 0.87 & 116 & $96 \cdot 7$ & 122 & 98.4 & 0.39 \\
\hline PGI (ng/ml) & & & & & 0.83 & & & & & 0.65 \\
\hline Mean & & & & & & & & & & \\
\hline SD & & & & & & & & & & \\
\hline PGII (ng/ml) & & & & & 0.15 & & & & & 0.11 \\
\hline Mean & & & & & & & & & & \\
\hline SD & & & & & & & & & & \\
\hline PGI:II & & & & & $0 \cdot 20$ & & & & & 0.24 \\
\hline Mean & & & & & & & & & & \\
\hline SD & & & & & & & & & & \\
\hline
\end{tabular}

CRP, C-reactive protein; SAA, serum amyloid component A; RU, relevant unit; PG, pepsinogen.

*By one-way ANOVA test or $\chi^{2}$ test.

†117 subjects in the per-protocol analysis were available in the low- and high-dosage groups, respectively.

Stratified analysis showed that there were no significant differences in the decrease in CRP or SAA levels between the two dosage groups by age categories (40s, 50s and 60s), sex, smoking or alcohol consumption. Similar results were observed after adjusting for sex, dietary intake of vitamin $\mathrm{C}$ (quartile), H. pylori titre, smoking status, alcohol consumption and BMI (data not shown).

\section{Discussion}

We did not observe any significant reduction of CRP or SAA levels in the low- or high-dosage groups after 5 years of ascorbic acid supplement use, although serum ascorbic acid concentration was higher in the high-dosage group than in the low-dosage group. We also did not observe any significant differences between the two groups in age, sex, smoking, alcohol consumption or body weight status.

The CRP and SAA levels in the present study were similar to those reported in other studies ${ }^{(3,20)}$. In the present study, based on cut-off points of $1.8 \mathrm{mg} / 1$ for CRP and $8.0 \mu \mathrm{g} / \mathrm{ml}$ for SAA, there were small numbers of CRP- or SAA-positive participants and there was no significant difference for either between the two dosage groups at baseline, respectively. We also applied other cut-off points for CRP- and SAA-positive status such as a CRP of $10 \mathrm{mg} / \mathrm{l}^{(21)}$ or by areas under the received curve ${ }^{(22)}$. By these criteria, the numbers of CRP- or SAA-positive participants remained similar and no significant differences existed between the two dosage groups. Nevertheless, the small number of CRP- and SAA-positive participants at baseline made it difficult to evaluate changes in CRP and/ or SAA status at follow-up. It might be possible that CRP and SAA were not highly sensitive markers for measuring chronic infection status, which contributed to the null outcome in the present study. On the other hand, the $500 \mathrm{mg} / \mathrm{d}$ supplement in the present study might not be sufficient to control chronic gastric infection, although cancer chemoprevention trials with more than $500 \mathrm{mg} / \mathrm{d}$ of vitamin $\mathrm{C}$ 
Table 2. Comparisons of serum ascorbic acid and inflammatory biomarkers between baseline and the 5-year follow-up

(Mean values and standard deviations or standard errors)

\begin{tabular}{|c|c|c|c|c|c|c|c|c|c|c|c|}
\hline & \multicolumn{5}{|c|}{ Low-dosage vitamin C, $50 \mathrm{mg}(n 117)$} & \multicolumn{6}{|c|}{ High-dosage vitamin C, $500 \mathrm{mg}(n 117)$} \\
\hline & \multicolumn{2}{|c|}{ Baseline } & \multicolumn{2}{|c|}{5 years } & \multirow[b]{2}{*}{$P^{*}$} & \multicolumn{2}{|c|}{ Baseline } & \multicolumn{2}{|c|}{5 years } & \multirow[b]{2}{*}{$P^{*}$} & \multirow[b]{2}{*}{$P \dagger$} \\
\hline & Mean & SE & Mean & SE & & Mean & SE & Mean & SE & & \\
\hline Serum ascorbic acid $(\mu \mathrm{g} / \mathrm{l})$ & & & & & $<0.01$ & & & & & $<0.001$ & $<0.001$ \\
\hline Mean & \multicolumn{2}{|c|}{$1 \cdot 38$} & \multicolumn{2}{|c|}{1.49} & & \multicolumn{2}{|c|}{1.35} & \multicolumn{2}{|c|}{1.73} & & \\
\hline SD & \multicolumn{2}{|c|}{0.32} & \multicolumn{2}{|c|}{0.29} & & \multicolumn{2}{|c|}{0.37} & \multicolumn{2}{|c|}{0.46} & & \\
\hline Dietary vitamin $C(\mu \mathrm{g} / \mathrm{l})$ & $123 \cdot 62$ & 1.06 & $121 \cdot 14$ & 1.06 & 0.79 & 123.52 & 1.06 & $123 \cdot 11$ & 1.06 & 0.88 & 0.78 \\
\hline CRP $(\mathrm{mg} / \mathrm{l})$ & 0.35 & $1 \cdot 12$ & 0.39 & $1 \cdot 12$ & 0.35 & 0.41 & $1 \cdot 14$ & 0.38 & $1 \cdot 12$ & 0.64 & $0.63 \ddagger$ \\
\hline SAA $(\mu \mathrm{g} / \mathrm{ml})$ & 3.87 & 1.07 & 3.94 & 1.06 & 0.88 & 4.09 & 1.09 & 3.85 & 1.07 & 0.57 & $0.61 \ddagger$ \\
\hline
\end{tabular}

CRP, C-reactive protein; SAA, serum amyloid component $A$

${ }^{*}$ By paired $t$ test.

†By one-way ANOVA test for the difference between the two dose groups at the 5-year follow-up.

$\ddagger$ Adjusted for age, sex, BMI, smoking status, alcohol consumption, dietary vitamin C, Helicobacter pylori status and baseline level of CRP or SAA.

supplementation have not shown consistent results on the beneficial effects ${ }^{(23,24)}$.

Human gastric carcinogenesis is a multistep and multifactorial process, with the initial stages of gastritis and atrophy linked to excessive salt intake and $H$. pylori infection ${ }^{(17,25)}$. H. pylori eradication can prevent the progression of precancerous gastric lesions and probably reduce the incidence of gastric cancer in those without advance lesions ${ }^{(26)}$. In the present study, CRP and SAA were not significantly reduced and the positive proportions of $H$. pylori were consistently higher $(\geq 92 \%)$ after 5 years of follow-up in both the lowand high-dosage groups ${ }^{(17)}$. It was possible that in the achlorhydric stomach, H. pylori infection might disappear, although the antibodies in the serum might maintain a longer time. Nevertheless, H. pylori infection potentially modulates the effects of vitamin $\mathrm{C}$ or vice versa ${ }^{(9)}$. Without eradicating the infection, ascorbic acid supplementation for participants with atrophic gastritis might have fewer effects on CRP/SAA control. However, studies on changes in CRP after H. pylori eradication are contradictory. Some studies have reported a significant reduction of CRP levels in subjects after $H$. pylori eradication by antibiotics ${ }^{(27)}$ or vitamin C supplementation ${ }^{(28)}$, while others have shown no significant reduction of CRP by anti-inflammatory or antibiotic treatment ${ }^{(20,29,30)}$. A Colombian study in gastritis patients, applying a 2-week anti-H. pylori treatment and/or a 6-year antioxidant supplement, showed that acute inflammation disappeared soon after the $H$. pylori treatment, while chronic inflammation responded at a slower pace, and the antioxidant effect was transient and disappeared after the 6 years of follow-up, while the anti- $H$. pylori treatment effect persisted for as long as patients remained free of $H$. pylori ${ }^{(23)}$. Also, subjects with non-metaplastic multifocal atrophic gastritis had the steepest declines if they cleared the bacteria, but had the sharpest increases if they did not ${ }^{(23)}$. The present study results appear to support the finding that ascorbic acid supplementation does not have much beneficial effect on chronic gastric infections, particularly without assigning the anti- $H$. pylori treatment.

There are several limitations in the present study. The most critical one is that we did not have a placebo group for comparison with the 50 and $500 \mathrm{mg}$ dosage groups ${ }^{(31)}$. However, the mean dietary intakes of vitamin C were 151.95 (SD 111.98) $\mu \mathrm{g} / \mathrm{l}$ and 147.93 (SD 99.81) $\mu \mathrm{g} / \mathrm{l}$ for the high- and low-dose groups, respectively, and the low-dose supplementation group was similar to or within $1 \mathrm{SD}$ of the estimated vitamin C intake level from foods. In the pilot study ${ }^{(32)}$ for the present trial, there were no significant differences in serum vitamin $\mathrm{C}$ concentrations between the placebo $(0 \mathrm{mg} / \mathrm{d})$ and the low-dose groups at 1,2 and 3 months of supplementation, respectively. Moreover, the purpose of the present study was to evaluate the effect of vitamin C supplementation $(500 \mathrm{mg} / \mathrm{d}$ ) compared with the normal level (the average consumption level of Japanese). Additionally, the similar mean dietary intake of vitamin $\mathrm{C}$ in the placebo group was seen in another trial $^{(33)}$. Therefore, the low-dose vitamin $\mathrm{C}$ supplementation group $(50 \mathrm{mg} / \mathrm{d})$ in the present study could be regarded as the placebo group for interpretation ${ }^{(34)}$. Second, the initial sample size was considered with estimated differences in accumulated gastric cancer incidence between the two study groups in 10 years rather with the changes in these biomarkers of atrophic gastritis in 5 years ${ }^{(10)}$. For example, to detect the $0 \cdot 15 \mu \mathrm{g} / \mathrm{ml}$ difference in SAA levels between the two dose groups at the 5-year follow-up, using the standard deviation in each group, 5\% type I error and 20\% type II error for estimation, 1030 subjects in each group are needed. The limited number of study subjects after changes in the initial study protocol had less statistical power for identifying the significance of CRP and SAA reductions between the two dosage groups. Third, IL- 6 and other immunological factors are thought to be mediators that stimulate CRP production ${ }^{(5,28,35)}$; however, we could not evaluate the CRP reduction as modified by ascorbic acid by using these factors because the data were unavailable. Since we did not conduct endoscopy for gastritis participants, we therefore could not evaluate the progression or regression of gastric lesions after ascorbic acid supplementation at the 5 -year follow-up ${ }^{(23,36,37)}$. Finally, since we only tested CRP and SAA two times, at baseline and the 5-year follow-up, any changes in their levels in the intervening time were not evaluated.

Some studies have reported that antioxidant supplementation, even at low doses, can have adverse effects on subjects at high risk for cancer or those with undiagnosed cancer ${ }^{(38,39)}$. 
It should be noted that some of the well-known beneficial effects of ascorbic acid administration are still only understood at the phenomenological level ${ }^{(40)}$. Currently, the Asia-Pacific guidelines on gastric cancer prevention do not recommend vitamin $\mathrm{C}$ supplementation for reducing the risk of gastric cancer $^{(26)}$.

In summary, we did not observe a significant reduction in CRP or SAA levels in atrophic gastritis participants with ascorbic acid supplementation of less than $500 \mathrm{mg} / \mathrm{d}$ at the 5-year follow-up. The present study suggests that ascorbic acid supplementation might not have much beneficial effect in individuals with chronic H. pylori infection. Further studies are needed in larger populations on the control of chronic infection and inflammation through ascorbic acid supplementation.

\section{Acknowledgements}

We wish to express our appreciation to the staff at the Hiraka General Hospital and the public health nurses at Sannai village office for their support and assistance with the study. This study was supported by Management Expenses Grants from the Government to the National Cancer Center and 3rd Term Comprehensive 10-Year Strategy for Cancer Control from the Ministry of Health, Labour and Welfare of Japan. Y. T. and S. T. designed the current research; Y. T. and S. T. initiated, modified and set the study protocols; Y. T., S. Sasaki, S. O. and S. Sasazuki implemented the study and collected the data; E. M. and S. Sasazuki analysed the data; E. M. and S. Sasazuki wrote the paper. All authors read and approved the final manuscript. The authors declare that there are no conflicts of interest.

\section{References}

1. Correa P (1988) A human model of gastric carcinogenesis. Cancer Res 48, 3554-3560.

2. Uemura N, Okamoto S, Yamamoto S, et al. (2001) Helicobacter pylori infection and the development of gastric cancer. $N$ Engl J Med 345, 784-789.

3. Sasazuki S, Inoue M, Sawada N, et al. (2010) Plasma levels of C-reactive protein and serum amyloid $\mathrm{A}$ and gastric cancer in a nested case-control study: Japan Public Health Centerbased prospective study. Carcinogenesis 31, 712-718.

4. Libby P (2002) Inflammation in atherosclerosis. Nature $\mathbf{4 2 0}$, 868-874.

5. Ilhan N, Ilhan Y, Akbulut H, et al. (2004) C-reactive protein, procalcitonin, interleukin-6, vascular endothelial growth factor and oxidative metabolites in diagnosis of infection and staging in patients with gastric cancer. World J Gastroenterol 10, 1115-1120.

6. Maury CP (1985) Comparative study of serum amyloid A protein and C-reactive protein in disease. Clin Sci (Lond) 68, 233-238.

7. Jarosz M, Dzieniszewski J, Dabrowska-Ufniarz E, et al. (1998) Effects of high dose vitamin C treatment on Helicobacter pylori infection and total vitamin $\mathrm{C}$ concentration in gastric juice. Eur J Cancer Prev 7, 449-454.

8. Zhang ZW \& Farthing MJ (2005) The roles of vitamin C in Helicobacter pylori associated gastric carcinogenesis. Chin $J$ Dig Dis 6, 53-58.
9. Jenab M, Riboli E, Ferrari P, et al. (2006) Plasma and dietary vitamin $\mathrm{C}$ levels and risk of gastric cancer in the European Prospective Investigation into Cancer and Nutrition (EPIC-EURGAST). Carcinogenesis 27, 2250-2257.

10. Tsubono Y, Okubo S, Hayashi M, et al. (1997) A randomized controlled trial for chemoprevention of gastric cancer in high-risk Japanese population; study design, feasibility and protocol modification. Jpn J Cancer Res 88, 344-349.

11. Tsugane S, Tsubono Y, Okubo S, et al. (1996) A pilot study for a randomized controlled trial to prevent gastric cancer in high-risk Japanese population: study design and feasibility evaluation. Jpn J Cancer Res 87, 676-679.

12. Omenn GS, Goodman GE, Thornquist MD, et al. (1996) Risk factors for lung cancer and for intervention effects in CARET, the Beta-Carotene and Retinol Efficacy Trial. J Natl Cancer Inst 88, 1550-1559.

13. National Cancer Institute (1996) Beta carotene and vitamin A halted in lung cancer prevention trial (press release). Washington, DC, 18 January 1996.

14. Miki K (1998) Pepsinogen Method. Tokyo: Igakushoin.

15. Miki K (1997) Basic evaluation of pepsinogen EIA kit. Jpn J Med Pharm Sci 37, 1013-1021 (in Japanese).

16. Watanabe Y, Kurata JH, Mizuno S, et al. (1997) Helicobacter pylori infection and gastric cancer. A nested case-control study in a rural area of Japan. Dig Dis Sci 42, 1383-1387.

17. Kim MK, Sasazuki S, Sasaki S, et al. (2003) Effect of five-year supplementation of vitamin $\mathrm{C}$ on serum vitamin $\mathrm{C}$ concentration and consumption of vegetables and fruits in middle-aged Japanese: a randomized controlled trial. $\mathrm{J} \mathrm{Am}$ Coll Nutr 22, 208-216.

18. Council for Science and Technology \& Ministry of Education, Science and Technology, Japan (2005) Standard Tables of Food Composition in Japan, the Fifth Revised and Enlarged Edition. Tokyo: National Printing Bureau.

19. Sasazuki S, Sasaki S, Tsubono Y, et al. (2003) The effect of 5-year vitamin C supplementation on serum pepsinogen level and Helicobacter pylori infection. Cancer Sci 94, 378-382.

20. Park SH, Jeon WK, Kim SH, et al. (2005) Helicobacter pylori eradication has no effect on metabolic and inflammatory parameters. J Natl Med Assoc 97, 508-513.

21. Kubota Y, Moriyama Y, Yamagishi K, et al. (2010) Serum vitamin $\mathrm{C}$ concentration and hs-CRP level in middle-aged Japanese men and women. Atherosclerosis 208, 496-500.

22. Cao L, Xu J, Lin Y, et al. (2009) Autophagy is upregulated in rats with status epilepticus and partly inhibited by vitamin $\mathrm{E}$. Biochem Biophys Res Commun 379, 949-953.

23. Mera R, Fontham ET, Bravo LE, et al. (2005) Long term follow up of patients treated for Helicobacter pylori infection. Gut 54, 1536-1540.

24. Greenberg ER, Baron JA, Tosteson TD, et al. (1994) A clinical trial of antioxidant vitamins to prevent colorectal adenoma. Polyp Prevention Study Group. N Engl J Med 331, 141-147.

25. Correa P (1992) Human gastric carcinogenesis: a multistep and multifactorial process - First American Cancer Society Award Lecture on Cancer Epidemiology and Prevention. Cancer Res 52, 6735-6740.

26. Fock KM, Talley N, Moayyedi P, et al. (2008) Asia-Pacific consensus guidelines on gastric cancer prevention. J Gastroenterol Hepatol 23, 351-365.

27. Kebapcilar L, Bilgir O, Cetinkaya E, et al. (2010) The effect of Helicobacter pylori eradication on macrophage migration inhibitory factor, C-reactive protein and fetuin-a levels. Clinics (Sao Paulo) 65, 799-802.

28. Block G, Jensen C, Dietrich M, et al. (2004) Plasma C-reactive protein concentrations in active and passive smokers: 
influence of antioxidant supplementation. J Am Coll Nutr 23, 141-147.

29. Pancorbo D, Vazquez C \& Fletcher MA (2008) Vitamin Clipid metabolites: uptake and retention and effect on plasma C-reactive protein and oxidized LDL levels in healthy volunteers. Med Sci Monit 14, CR547-CR551.

30. Eshmuratov A, Nah JC, Kim N, et al. (2010) The correlation of endoscopic and histological diagnosis of gastric atrophy. Dig Dis Sci 55, 1364-1375.

31. Sasazuki S, Hayashi T, Nakachi K, et al. (2008) Protective effect of vitamin C on oxidative stress: a randomized controlled trial. Int J Vitam Nutr Res 78, 121-128.

32. Sasaki S, Tsubono Y, Okubo S, et al. (2000) Effects of threemonth oral supplementation of beta-carotene and vitamin $\mathrm{C}$ on serum concentrations of carotenoids and vitamins in middle-aged subjects: a pilot study for a randomized controlled trial to prevent gastric cancer in high-risk Japanese population. Jpn J Cancer Res 91, 464-470.

33. Huang HY, Appel LJ, Croft KD, et al. (2002) Effects of vitamin $\mathrm{C}$ and vitamin $\mathrm{E}$ on in vivo lipid peroxidation: results of a randomized controlled trial. Am J Clin Nutr 76, 549-555.

34. Kim MK, Sasaki S, Sasazuki S, et al. (2004) Long-term vitamin $\mathrm{C}$ supplementation has no markedly favourable effect on serum lipids in middle-aged Japanese subjects. $\mathrm{Br}$ J Nutr 91, 81-90.

35. Castell JV, Gomez-Lechon MJ, David M, et al. (1990) Acutephase response of human hepatocytes: regulation of acutephase protein synthesis by interleukin-6. Hepatology $\mathbf{1 2}$ 1179-1186.

36. Correa P, Piazuelo MB \& Camargo MC (2004) The future of gastric cancer prevention. Gastric Cancer 7, 9-16.

37. Correa P, Fontham ET, Bravo JC, et al. (2000) Chemoprevention of gastric dysplasia: randomized trial of antioxidant supplements and anti-Helicobacter pylori therapy. J Natl Cancer Inst 92, 1881-1888.

38. Qiao YL, Dawsey SM, Kamangar F, et al. (2009) Total and cancer mortality after supplementation with vitamins and minerals: follow-up of the Linxian General Population Nutrition Intervention Trial. J Natl Cancer Inst 101, 507-518.

39. Hercberg S, Kesse-Guyot E, Druesne-Pecollo N, et al. (2010) Incidence of cancers, ischemic cardiovascular diseases and mortality during 5-year follow-up after stopping antioxidant vitamins and minerals supplements: a postintervention follow-up in the SU.VI.MAX Study. Int J Cancer 127, $1875-1881$.

40. Mandl J, Szarka A \& Banhegyi G (2009) Vitamin C: update on physiology and pharmacology. Br J Pharmacol 157, 1097-1110. 